\title{
多相型液／液分散系の調製
}

\author{
松本幸雄
}

\section{Methods for Preparing Liquid/Liquid Type Multiple-Phase Dispersions}

\author{
Sachio Matsumoto
}

\begin{abstract}
This article reviews the work on the technique for preparing a variety of liquid/liquid type multiple-phase dispersions. The major contents are divided into three sections : principle for obtaining multi-lamellar and single compartment lipomes, two-step procedure for emulsification in preparing the water-in-oil-in-water (W/O/W) type multiple-phase emulsions by use of liquid paraffine and ordinary emulsifying agents, and application of the two-step procedure for providing liposome-like lipid vesicle suspensions composed of the mixture of purified soy lecithin and Span 80 .
\end{abstract}

\section{1. はじめに}

ニュートン液体やフック固体のように，頭の中で理想 化された物体を除いて，実在するあらゆるものはそれぞ れ個有の成分をもち，個有の性質と機能を備えている。 したがって, 多くの場合に, われわれは未知の物体に対 しその構成々分について興味をもち，その成分によって そのものの性質や機能を理解しようとする。自然科学の 学習においてつちかわれたわれわれこのよらな態度は, 分析された要素に単純な加成性がなりたつところの線形 の科学に基盤を置いたものである1。ところが, 晡乳動 物の血液と筋肉のそれぞれの成分を比較してみると, 余 程精度の高い要素分析の結果を持たない限り, そこに大 きな差異を認めることはできない。

これは極端な例には違いないが，多くの成分組成を有 するもの程, その性質や機能は成分の組織形態, すなわ ち分散状態との関連に拈いて考察されることが必要にな る。生体膜に関する研究においてその典型の一つそ見る ことができるが2,3)，生体系に限らず香粧品や食品等で もとれらの物理学的性質は, 成分の分散状態に関する知 見にもとついて解釈されなければならない部分がさわめ て多い4。しかも，その多くは多成分不均一混合系であっ て，その分散状態を多相平衡のような概念だけで理論的

大阪府立大学農学部, 堺市百舌鳥梅町

Department of Agricultural Chemistry, College of Agriculture, University of Osaka Prefecture, Mozu-umemachi, Sakai, Osaka, Japan 591
に演繹することは困難な非線形の系なのである。

筆者は, このような問題を取り扱らとき, 可及的に純 粋な成分を用いて単純なモデル系を人工的に組み立て, 実験によって得られたモデル系の諸性質をとの分散状態 と対比させることが, 複雑な分散系の挙動を説明するの に近似的に有用であることを指摘してきた ${ }^{5,6,7)}$ 。この意 味から, 本稿で筆者に課せられた多相型液／液分散系の. 調製法以関する記述も, その内容は筆者が参考にし, あ るいは自ら作製することを意図してきたモデルとしての 分散系に関するものであり，そのいずれもが通常のエマ ルションとは異なった三相以上のいわゆる小胞体構造の ものである。そして，これらの系がモデルとしてどの程 度有用であるかを明らかにすることは，筆者自身の今後 の課題でもある。な挔, 多相型分散系の一つである W/ $\mathrm{O} / \mathrm{W}$ 型エマルションが, すでに医学・楽学の分野で動 物実験における薬剂投与に利用されているとする指摘も あるが8)，未だ本質の十分明らかでない系を実際的応用 の場に引き出すのは筆者の立場ではない。

\section{2. リポゾーム}

生体成分の中には界面活性を有するものが少なくない が，就中燐脂質については1960年代に入ってから生物学 の分野で多くの研究が行なわれた材料である。すなわち, 生体としての多くの重要な機能が営まれていると考兑 られる生体膜の主成分が，種々の燐脂質で構成されてい るからである。燐脂質そのものの性質に関する研究と同 
時に、これを用いて生体膜のモデルを調製する試みも行 なわれた。その一つが, 花井らおおよび Mueller やTien ら ${ }^{10)}$ にっって調製された脂質の黑膜 (Black lipidmembrane) であり, 他のものが Bangham 一派 ${ }^{11}$ に上っ て，作られたリポゾーム（Liposome）である。特に， 後者は，実在の生体顆粒に匹敵するよらな形態のもので あることから，種々の生物実験における忉料として利用 されている12)。

燐脂質の成膜性は，その状態四から理解することがで きる。Fig.-1 は, Chapman ら ${ }^{13)}$ が得た合成のジパ ミトイルホスファチジルコリンの水との 2 成分系におけ る状態図であるが，一般に燐脂質の結晶を加熱していく と, 結晶が融解して等方性の液体に变化するまでに, 異 方性の液晶状態があらわれる温度領域が存在することが わかる。この温度領域で, 燐脂質の脂肪酸部分は融けた 状態にあるが, ヘッドグループと呼ばれる親水性部分は 2 方向に規則的に配列して扮り，全体としてスメクト型 中間相 (Smectic mesophase) に分類される状態にあ る。このような系に少量の水を加觉ると, 分子相互の規 則的配列を乱すことなく水はへッドグループ間に入り込 む, これが mesomorphic lamellar 相である。このま ま温度を下げると，燐脂質の脂肪酸部分は結晶化する が，水を分離することはない。これがゲル相である。い っぽう, mesomorphic lamellar 相にさらに水を加えて いくと,ゲル相への迷移温度は低下し，やがて一定にな ると同時に相分離が生じ， mesomorphic lamellar と水 との潉合状態があらわれる。

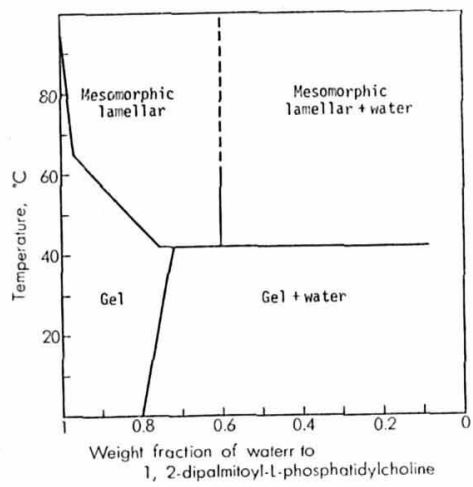

Fig. -1 Phase diagram of the 1,2-dipalmitoyl-Lphosphatidylcholine/water system ${ }^{13)}$.

Fig. -2 は，水中に分散した lamellar 相の一つを， ユニレバー研究所の電影グループが freeze etching に
より撮影した電顕像で， 円環状の幾重もの lamella が 一個の粒子を形成している状況がわかる。これが，多重 啳リポゾーム (Multilamellar liposome) と呼ばれてい るもので, この lamellar 相の中の一枚の lamella が, 燐脂質の 2 分子膜からなる膜モデルの实体である。

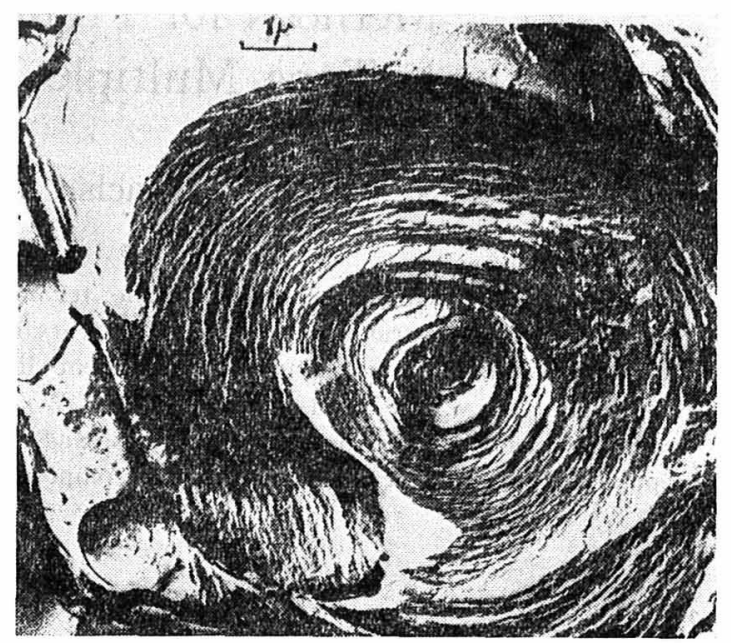

Fig-2 Electronmicrograph of a multilamellar liposome prepared from egg lecithin.

多重層りポゾームは，容易に調製することができる。 すなわち，溶媒に溶解させた粼脂質を減圧下に置いて溶 媒を揮散除去すると, 燐脂質の各分子は容器の内面で 2 力向に配列した累積膜を形成する。これに電解質水溶液

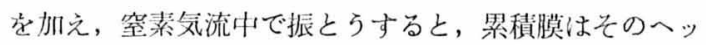
ドグループ間に水溶液を取り込んで膨潤し, やがて器壁 から順次遊離して多重畨リポゾームのサスペンションが 生成する。Fig.-2 からも示唆されるよらに, その層状 構造には幾重もの水の相が介在するので, 多重層りポゾ 一ムのサスペンションは, 多相型液/液分散系の一典型 であると見なすことができる。

このサスペンションを, さらに窒素気流中で超音波処 理すると（例总ば， $4^{\circ} \mathrm{C}$ において $20 \mathrm{kHz}$ の超音波を約 2 時間照射), 多重層りポゾームの大部分は一枚膜リポ ゾーム (Single compartment liposome) と呼ばれる小 胞体に変化与る。その一個については，一枚の脂質 2 分 子膜に聿まれた直径污 $200 \sim 600 \AA$ 程度の水の小胞体で あって, 形は多様である。超音波処理の終ったりポゾー ムのサスペンションを，例えばセファロース $4 \mathrm{~B}$ のカラ 么に通すと, 大きさの活ぼ一様な一枚膜りポゾームの> ラクションを得ることができる。同時に，小胞体の内部 と外部とで組成の異なる水相を設定することが可能であ 
るからこのよらな系を利用して，脂質 2 分子膜を種々 の物質が拡散し透過する状況が観測されるようになって いる14)。いっぽう, 小胞体としてはきわめて小さく, 非 球形であるといら形態は，モデル系としては不利な面も あるように思われる。

\section{3. $\mathrm{W} / \mathbf{O} / \mathrm{W}$ 型多相エマルション}

一枚膜りポゾーム系に执いて，微細な小胞体を構成す る脂質 2 分子膜は, その状態が平衡にあるので, 膜面の 大きな曲率の問題を除くと一応熱力学的に安定な系であ ると考えられる。これに対し, 筆者は, 通常の乳化操作に よって成分的にも形態的にも通常のエマルションと同等 の状態で小胞体構造を形成させるための条件を検討する ことを意図した。通常の乳化操作で多相エマルションが 偶然に現れることが見い出されているが15)，その機構に ついては不明確であるからである。また, 熱力学的には 不安定な分散系一般の特質に照らして, 多相エマルショ ソのモデルとしての有用性があると考壳たからである。

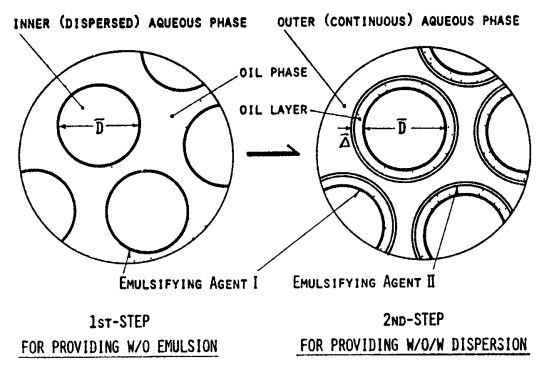

Fig. -3 Two-step procedure for emulsification in preparing the $\mathrm{W} / \mathrm{O} / \mathrm{W}$ type multiplephase emulsion ${ }^{16)}$.

そこで, 形態的には一枚膜りポゾームに相当するとこ ろの, 油膜に囲まれた一個の水の小胞体が水中で個々の 分散粒子を構成するような系を高い生成率で調製するこ とを試みるために, 予備実験の結果から以下のような手 順を決めた ${ }^{16)}$ 。

まず乳化法について, 最初に通常の $\mathrm{W} / \mathrm{O}$ 型エマルシ ョンを調製する(一次乳化)。すなわち, 親油性乳化剤 を含む油相の一定量に，小胞体内部の成分となるべき 水相（内水相）の所定量を徐々に添加しながら攪找を 続ける。この翼拌はどのような装置で行なってもよい が, 流動パラフィンのよらに粘度の高い油に水を分散さ せるとき，筆者らは低速回転のピンミキサー（88 rpm） を使用した。ついで, 得られた W/O 型エマルション を, 小胞体の分散媒（外水相）となるべき親水性乳化剂
水溶液と混合し, 高速の攪拌機 $(2000 \mathrm{rpm} \sim 3000 \mathrm{rpm})$ を用いて空気の混入を防ぎながら数分間攪科する（二次 乳化)。以上が二段階乳化法 ${ }^{16)}$ と呼んでいる $\mathrm{W} / \mathrm{O} / \mathrm{W}$. 型多相エマルションの調製法であって, 特別の技術や装 置を必要としない簡単な方法である。Fig.-3 に, 二段 階乳化法を模式的に示した。

つぎに, この実験を進める上で重要であるのは, 二段 階乳化法で成分の種類や量を変えて試料を調製しなが ら, 目的とする小胞体の生成率を正確に測定しなければ ならないことである。そのため，筆者らが考えたのは， ブドー糖をマーカーとしてその内水相から外水相への移 行量を求める方法であった。すなわち, 一次乳化の際,

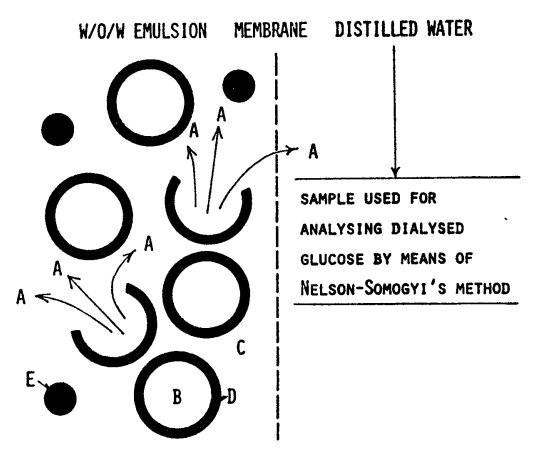

Fig.-4 Schematic illustration of dialysis in measuring the formation of the $\mathrm{W} / \mathrm{O} / \mathrm{W}$ type multiple-phase emulsion. A : Migrated glucose from the inner aqueous-phase globule, B : Inner aqueous-phase globule, C : Outer apueous-phase, D : Oil layer, E : Oil globule appearing after the rupture of the oil layer ${ }^{16)}$.

油中に分散させる水相にあらかじめ $0.5 \%$ のブドー糖を 溶解して扣き, 二次乳化が終了した直後の試料の一部を 一定量の蒸留水に対して透析し, 透析平衡に達したのち 蒸留水の一部についてそこに存在するブドー糖の量を, Nelson-Somogyi の方法17) で分析する。このようにし て得られたブドー糖の量が $a \mathrm{~g} / \mathrm{m} l$ であったとすると, $\mathrm{W} / \mathrm{O} / \mathrm{W}$ 型多相エマルションの生成率はつぎのよらに 計算される。

$$
\text { 生成率 }(\%)=100-100 a /\left[c /\left(v_{1}+v_{2}+v_{3}\right)\right]
$$

ここに, $c$ は透析に用いられた試料に含まれるブドー糖 量 $(\mathrm{g}), v_{1}, v_{2}, v_{3}$, は同じく透析に用いられた試料中の 内水相体積 $(\mathrm{m} l)$, 外水相体積 $(\mathrm{m} l)$, 抢上び蒸留水の体 積 $(\mathrm{ml})$ である。Fig. -4 に, この方法が膜式的に示さ 
れている。

なお，生成した $\mathrm{W} / \mathrm{O} / \mathrm{W}$ 型多相エマルション系の小 胞体の油膜の厚さは, 一枚膜 リポゾームの場合と異な り, 一次乳化に使用した油相成分の量に比例して変化す る筈であるので, つぎのように考えて油膜の厚さの平均 值を推定した。すなわち, 二次乳化の際, W/O 型エマ ルションの連続相であった油相成分が分散相である水粒 子の大きさに比例してその表面に分配されるとすると， $\mathrm{W} / \mathrm{O}$ 型エマルションの分散相体積分率 $\phi w / O$ はつぎの ように計算される。

$$
\phi_{W /} o=\bar{D}^{3} /(\bar{D}+2 \bar{\Delta})^{3}
$$

ここに, $\bar{D}$ は小胞体になる分散粒子の平均直径, $\overline{~ は 二 ~}$ 次乳化によって小胞体表面に形成された油膜の厚さの平 均值である (Fig.-3 参照)。したがって，

$$
\bar{\Delta}=\left[\left(\bar{D}^{3} / \phi_{W / 0}\right)^{\frac{1}{3}}-\bar{D}\right] / 2
$$

$\phi W / O$ の值は一次乳化の際に人為的に正確に調節される ので, 油膜の厚さもかなり任意に調整することが可能で ある。

さて，筆者らは，油相に流動パラフィンを，乳化郕に 合成界面活性剂を用いて $\mathrm{W} / \mathrm{O} / \mathrm{W}$ 型多相エマルション の調製を試みた。その結果 ${ }^{16)}$ を要約すると,つぎのよ らである。

1）親油性乳化剤として, Span 20 ないし Span 80 が 有効であり, その使用量が多い程 $\mathrm{W} / \mathrm{O} / \mathrm{W}$ 型多相工 マルションの生成率が向上する。

2）親水性乳化剂には, ポリオキシェチレン系の非イ 、オン性界面活性剤を可及的に少量使用することが高い 生成率を得るために必要であって, イオン性界面活性 剤はその使用量にかかわらず良い結果を与充ない。

3) 二次乳化の際, 親水性 乳化剂水溶液と混合する $\mathrm{W} / \mathrm{O}$ 型エマルションの量が相対的に多い程, 試料の 生成率は良い。

4）以上の諸条件が具備されると, $\mathrm{W} / \mathrm{O} / \mathrm{W}$ 型多相エ マルションの生成率と油膜の厚さとは無関係であり,

約 $300 \AA$ の厚さの油膜を有する試料を, $95 \%$ 以上の 生成率で得ることもできる。

これらの結果を総合すると, W/O/W 型多相エマルシ ョンの生成に対する要因の一つは, 使用した親油性乳化 剤と親水性乳化剂の量比であることに気付く。Fig. -5 は, Span 20 とTween 20 との組み合わせを用い, 種々 の条件で調製を試みた $\mathrm{W} / \mathrm{O} / \mathrm{W}$ 型多相エマルションの 生成率を, Span 20 の Tween 20 に対する重量比で整

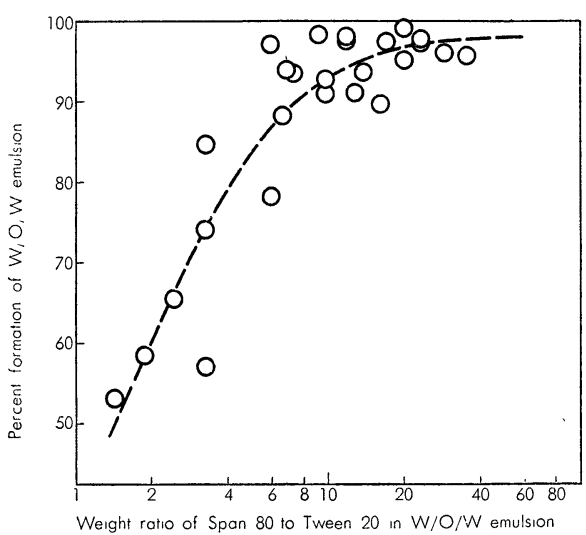

Fig. -5 Plot of the $\mathrm{W} / \mathrm{O} / \mathrm{W}$ emulsion formation against the weight ratio of Span 80 to Tween 20 in the $\mathrm{W} / \mathrm{O} / \mathrm{W}$ systems, calculated from the constitution of various $\mathrm{W} / \mathrm{O} / \mathrm{W}$ emulsion samples ${ }^{16)}$.

理した結果である。Fig.-5 からら明らかなように，この 乳化剤の組み合わせでは, 油膜の厚さや小胞体の分散相 濃度には無関係に，系全体の中で親水性乳化刘である Tween 20 の 1 部に対し親油性乳化剂である Span 20 が 10 部以上含まれると，目的とする試料の生成率は $90 \%$ 以上に達する。これと同様な傾向は, Fig. -6 に示され

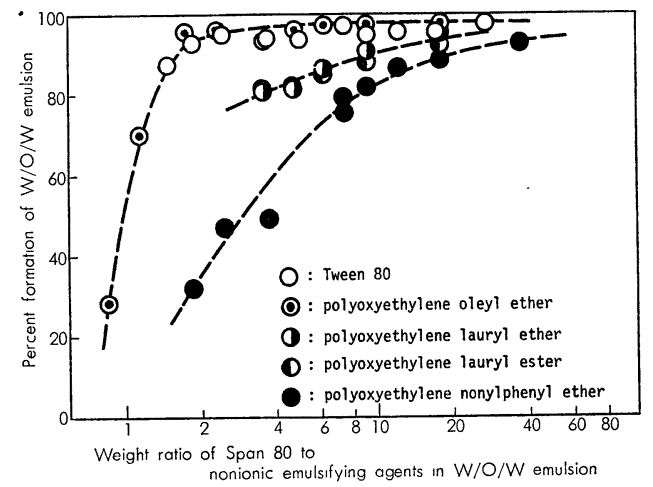

Fig.-6 Plot of the $\mathrm{W} / \mathrm{O} / \mathrm{W}$ emulsion formation against the weight ratio of Span 80 to the nonionic emulsifying agents in the $\mathrm{W} / \mathrm{O} / \mathrm{W}$ systems ${ }^{16}$.

るように，他の一連の親水性乳化剂を用いた場合にもみ られるが，90\% 以上の試料生成率を得るための親油性 乳化剤との重量比は, 親水性乳化剂の蹯水基の種類と鎖 長とに関係があることが示唆される。

これに対する筆者らの解釈は, 定性的ではあるがつぎ のようである。すなわち, 二次乳化の際, 小胞体表面に 
形成される液状の油膜の外側は親油性・親水性両乳化刘 の混合膜で覆われると同時に, 親水性乳化剂のミセル水 溶液である外水相と接することになる。したがって，以 後可溶化平衡に達するまで, 親油性乳化剂は親水性乳化 剂と混合ミセルをつくり，油相から外水相へ移行する。 この現象が顕著であると, 小胞体表面に括汁る油膜状態 の保持能力が失なわれ, 結局小胞体の生成率は低下す る。この上らな二次乳化に抢ける過渡的な現象が試料の 生成率に影響するか否かは, 油相中の親油性乳化剂と外 水相中の親水性乳化剂の量比によって支配されると考え られるのである。

な㧍, 生成率の高い多相エマルションでも, その広大 な油／水界面の界面積を小さくする方向への変化, すな わち熱力学的に不安定な系であることにもとづく油膜の 破壞が, 必然的に連続して生じる。筆者らは, 多相エマ ルションの小胞体構造の 持続性を測定する方法を検討 し ${ }^{18,19)}$, 持続性の機構について考察を行なっている。ま た, 内水相にあらかじめ水溶性物質を添加しておくと, 厚い液状の油膜を介して内外水相間に浸透圧が作用する 現象も見い出されている ${ }^{20)}$ 。れには, 両乳化剤のミセ ルが，物質移動の担体として重要な役割を果たしている 状況が考えられる。

いっぽう, 可食性の $\mathrm{W} / \mathrm{O} / \mathrm{W}$ 型多相エマルションを, オリーブ油, 大豆レシチン, Span 80 およよび䒫糖脂肪酸 エステルを用いて，二段階乳化法により調製でさること が最近明らかにされたが211, その詳細は他の機会に述べ る。

\section{4. 脂質小胞体サスペンション}

前述のように, 一枚膜りポゾームは, 生休膜モデルと しての特質を備えた生物学実験上有用な材料であるが， いっぽうではきわめて微少な非球形の小胞体であること による欠点をるつ。このことから，筆者らは，リポゾー ムとしての機能をもつと同時に通常のエマルション粒子 の大きさを有する球形脂質小胞体を, 簡単な $\mathrm{W} / \mathrm{O} / \mathrm{W}$ 型多相エマルションの調製法を改良して作製することを 試みた222（Fig, -7)。

この実験に用いた材料は，脂質膜成分として溶媒分画 法 ${ }^{23)}$ により精製された大豆レシチン，同じく Span 80, 脂質の溶媒扣よび W/O 型エマルションの分散媒として の n一ヘキサン, 脂質小胞体の分散剤としての一連の親 水性界面活性剂等である。これらのらち，n一ーキサンと 親水性界面活性剂は; 試料調製の過程で必要ではあるが 脂質小胞体を構成する成分ではなく，いずれも調製の途

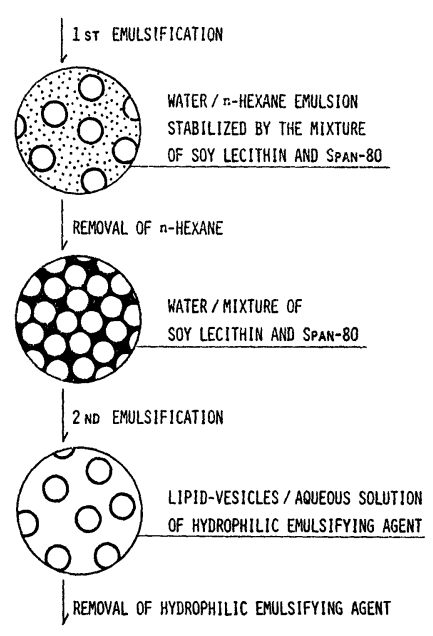

Fig. -7 Schematic diagram of the procedure for preparing the lipid vesicle systems ${ }^{22)}$

中の段階で除去される。すなわち, 適当量の $\mathrm{n}$ 一へキサ ンに所定量のレシチンと Span 80 を溶解し，これに小 胞体の成分となる水を少量づつ添加しながら攪拌して $\mathrm{W} / \mathrm{O}$ 型エマルションとする。この操作は一次乳化に相 当するものであるが，攪捧は高速で行なら必要がある。 得られた W/O 型エマルションを, ロータリーエバポレ 一ターのなす型容器に移つし, 隇圧下に置いて n一へキ サンを除去する。このとき， n一へキサンの蒸発の潜熱 によって, 試料の温度が低下するのを防ぐようにする。 やがて, W/O 型エマルションは, 脂質混合物中に水粒 子が分散したスラリー状ないしは粘稠なクリーム状のも のに変化する。ついで，このものを親水性界面活性剤水 溶液の所定量と混合し, 脂質小胞体のサスペンションと する。その一部を小胞体生成率測定用試料とし，残部を 蒸留水に対して十分に透析し, 剩余の界面活性剂を系外 に除去すると、リポゾームと同等の脂質小胞体サスペン ションが得られることになる。この場合，小胞体の脂質 膜は lamellar 構造を有している筈であり，したがって リポゾームと同じ理由により，この小胞体はきわめて安 定な状態を保持すると考光られる。Fig.-8 は，上記の 透析操作において, 脂質小胞体内部にあらかじめ溶解し ておいたブドー糖が透析外液へ移行する量を，W/O/W 型多相エマルションのそれと比較したもので，5 日間の 透析に対し脂質膜の破壊によるブドー糖の透析外液への 移行は認められない。な和，小胞体の生成率の測定に は, W/O/W 型多相エマルショシの項で述べた方法をそ のまま用いた。 


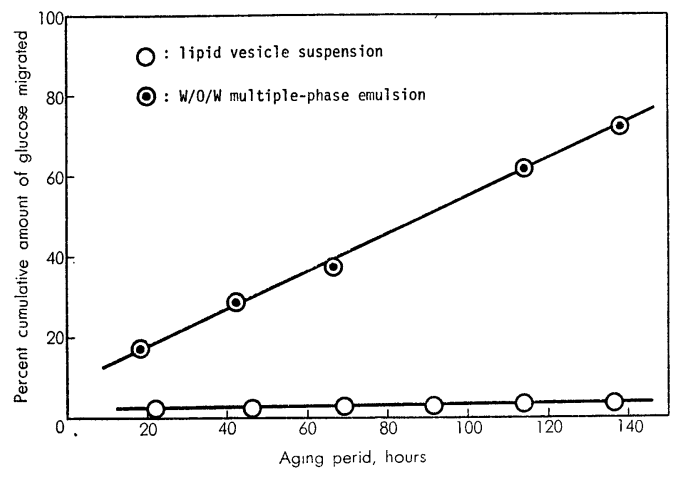

Fig. -8 Cumulative amounts of glucose which migrated from the dispersed apueous comparments in a lipid vesicle sample compared to those in a $\mathrm{W} / \mathrm{O} / \mathrm{W}$ emulson as a function of aging (suspending medium : apueous solution of $10 \mathrm{mM}$ Tween 80 , $\bar{\Delta}: 83 \AA$ for lipid vesicle sample and $350 \AA$ for $\mathrm{W} / \mathrm{O} / \mathrm{W}$ emulsion when $\bar{D}=1 \mu \mathrm{m})^{22)}$.

以上の材料および手順によって, 脂質小胞体の生成率 に対する要因を検討した結果は，つぎのようである。一 次乳化ののち, 減圧下で W/O 型エマルションの分散媒 である $\mathrm{n}$ ーヘキサンを除去したとき，均一な持続性のあ るスラリ一状の水／脂質混合物分散系を得ることが，最 終的に高い生成率の試料を得るのに必要な条件であり， そのためには小胞体の脂質膜成分となるレシチンと Span 80 との混合比に最適值を選ばなければならない。

Fig.-9 は，脂質小胞体の生成率におよぼすレシチンと Span 80 との混合比の影響を調べた結果であり，90\%以 上の試料生成率を得るためには，上記両脂質成分の重量

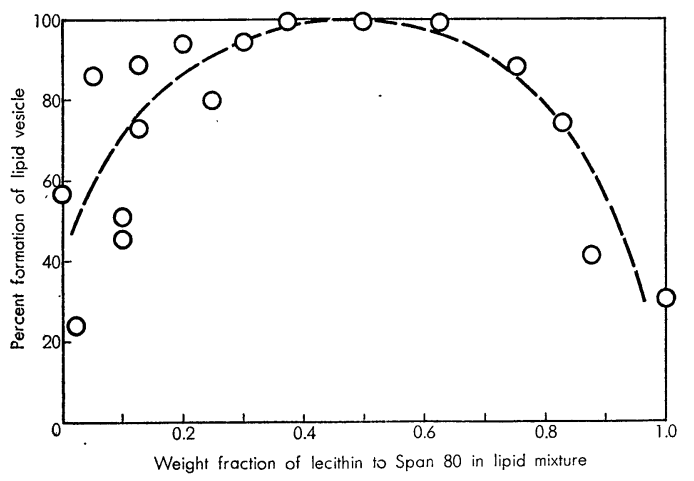

Fig, -9 Effect of the weight fraction in the lipid mixture of soy lecithin to Span 80 on the formation of the lipid vesicle sample (suspending medium : aqueous solution of $10 \mathrm{mM}$ Tween $80, \bar{\Delta}: 590 \AA$ when $\bar{D}=1 \mu \mathrm{m})^{22)}$.
分率を 0.35 から 0.65 の範囲に設定しなければならない ことがわかる。この範囲の組成を有する脂質混合物は, 膜状態に扣いて高い力学的強度を有するものと考えられ る24)。他の要因には，二次乳化の操作に相当するところ の, 脂質小胞体サスペンションの調製の際に使用する親 水性界面活性剂の種類と濃度の問題がある。Tale-1 は, この操作に用いた界面活性剂の種類と濃度および脂質小 胞体の生成率の関係をまとめたもので, W/O/W 型多相 エマルションの場合と同様, 界面活性剤濃度の減少とと もに試料生成率は増加し, 最適值を越えてさらにその濃 度が減少すると小胞体の分散が劣化するが, この場合イ オン性の界面活性剂も使用できることが多相エマルショ ン系の場合と異なる点である。なお，二次乳化後の透析 によって, 親水性界面活性剤がどの程度除去されるかに ついては，未だ正確な測定を行なっていないが，ドデシ ル硫酸ナトリウム（SDS）を用いて調製し，2 日間透析 した試料について誘電測定が行なわれた結果, SDS の 残存は認められていない25)。

Table-1 Effect of type and concentration of the hydrophilic surfactants used for dispersing the water-in-lipid mixture system into water on the formation of the lipid vesicle samples (weight fraction of lecithin to Span $80: 0.5)^{22)}$.

\begin{tabular}{|c|c|c|c|c|c|}
\hline $\begin{array}{l}\text { Concentrationn of } \\
\text { surfactant in the } \\
\text { aqueous medium (mM) }\end{array}$ & $\frac{\mathrm{V}}{\mathrm{SDS}}$ & $\begin{array}{l}\text { esicle } \\
\text { CTA } \\
-\mathrm{Br}^{*}\end{array}$ & $\begin{array}{l}\text { form } \\
\text { POE- } \\
\text { OE** }\end{array}$ & $\begin{array}{l}\text { Twe } \\
\text { en80 }\end{array}$ & 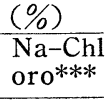 \\
\hline 2.5 & 98 & 85 & - & - & - \\
\hline 5 & 98 & 79 & - & 90 & 97 \\
\hline 10 & 53 & 69 & 99 & 96 & 94 \\
\hline 20 & 0 & 47 & 98 & 90 & - \\
\hline 30 & 0 & 36 & 97 & 79 & - \\
\hline 40 & 0 & 5 & 55 & 19 & - \\
\hline 50 & 0 & 113 & $34-83$ & 10 & - \\
\hline
\end{tabular}

* Cetyl trimethyl ammoniumbromide

** Polyoxyethylene oleyl ether

*** Sodium copper chlorophylin

$\mathrm{W} / \mathrm{O} / \mathrm{W}$ 型多相エマルションの場合と同様, 脂質小胞 体でも生成率とは無関係に脂質膜の厚さを調節すること が可能である。例えば, n一ヘキサンに溶解させるレシチ ンと Span 80 の量を少なくして W/O 型エマルション を作り，減压下での n一ヘキサンの除去を注意深く行な えば, きわめて濃厚な水／脂質 混合物 型分 散系が 得ら れ，このものは薄い脂質膜からなる小胞体を調製する素 材となる。この場合も, 脂質膜の厚さは, n一ヘキサン除 
去後の系の 分散相体積分率を $\phi W / O$ とし，分散粒子の 直径を $D$ とすれば，(3) 式から推定することができる。 Table-2 は， $\phi W / O$ を変えて調製した試料の生成率を示 したもので，脂質 2 分子膜に相当する厚さの系が高い生 成率で得られている点は, この実験の目的からして重要 である。また， $\phi$ W/0 を小さくすると，厚い脂質膜に囲 まれた小胞体が生成するが，その膜の実体は，脂質 2 分 子膜の倍数の厚さをもった lamellar 構造のものである 笘である。

Table-2 Interrelationship between the volume fraction of the aqueous compartment in the water-in-lipid mixture system $\phi w / O$ the thickness of the lipid layer $\vec{\Delta}$ on the surface of the apueous compartments, and the formation of the lipid vesicle samples ${ }^{22}$.

\begin{tabular}{|c|c|c|c|}
\hline \multirow{2}{*}{$\phi W / O$} & \multicolumn{2}{|c|}{$\bar{\Delta}(\AA)$} & \multirow{2}{*}{$\begin{array}{c}\text { Vesicle formation } \\
(\%)\end{array}$} \\
\hline & $\overline{\bar{D}}=1 \mu \mathrm{m}$ & $\bar{D}=2 \mu \mathrm{m}$ & \\
\hline 0.714 & 590 & 1180 & 99 \\
\hline 0.800 & 380 & 760 & 96 \\
\hline 0.834 & 310 & 620 & 71 \\
\hline 0.875 & 230 & 460 & 92 \\
\hline 0.900 & 180 & 360 & 98 \\
\hline 0.923 & 135 & 270 & 97 \\
\hline 0.952 & 83 & 166 & 96 \\
\hline
\end{tabular}

Weigh fraction of lecithin to Span $80: 0.5$

Suspending medium : aqueous solution of $10 \mathrm{mM}$ Tween 80

$$
\text { おわりに }
$$

香粧品の分野に打けるエマルションの研究は, 化粧用 クリームの歷史とともに非常に古いものであり，そこに は多くの興味ある知見や技術上の情報が集積されている ように思われる。いっぽう，エマルションは，成分組成 の多様性と形態の特異性から, 最近, 生物学の分野から 環境污染の防御の問題にいたるまで，広い応用範团をも つものとして注目されている材料でもある。このこと は, 最初に述べたように, 複雑な非線形の系を, 好むと 好まざるとにかかわらず报わなければならない必然性 が，多くの研究の分野に析出していることを意味する。 このような問題とかかわり合っている筆者も含めた多く の研究者にとって, 香籸品研究の分野の成果に期待する ところがきわめて大きい。

最後に，筆者に本稿の執筆をすすめて下さった（株） クラブコスメチックス 鈴木一成博士に対し，厚く御礼 を申し上げる。

\section{文献}

1）柴谷篤弘, “反科学論” p. 57, (1973) みすず書房

2) H. TiTien, "Bimolecular Lipid Membranes" in R. J. Good et al (ed.) "Techniques of Surface and Colloid Chemistry" Vol. 1, p. 109, (1972) Marcel Dekker, Inc., New York.

3) D. M. Small, J. Colloid Interface Sci., 58, 581 (1977)

4）松本幸雄，“乳化食品に括ける油相成分の分散状 態とその测定の意義” 松本幸雄編 “食品の物性” 第 3 集 p. 1 (1977) 食品資材研究会

5）松本幸雄，化学と生物，12，670（1974）

6）松本幸雄, 化学と工業, 28, 488 (1975)

7）松本幸雄, 化学, 31, 332 (1976)

8）竹口紀晃, 私信

9) T, Hanai, D. A. Haydon and J. Taylor, Proc. Roy. Soc. (London). A 281, 377. (1964)

10) P. Mueller, D. O. Rudin, H. TiTien and W.C. Wescotte, Nature, 194, 979 (1962)

11) A.D. Bangham, M. M. Standish and J. C. Watkins, J. Mol. Biol., 13, 238 (1965)

12) A.D. Bangham, Progr. Biophys. Mol. Biol., 18, 29 (1968)

13) D. Chapman, R. M. Williams and B.D. Ladroore, Chem. Phys. Lipids, 1, 445 (1967)

14）井上圭三, “リポゾーム実験法と応用”別冊蛋白 質・核酸・酵素 “生体膜実験法 下” p. 185, （1974）共立出版.

15) P. Sherman, "General Properties of Emulsions and Their Constituents" in P. Sherman (ed.) "Emulsion Science" p.206, (1968) Academic Press, London; 佐々木恒孝, 花井哲 也, 光井武夫訳 “エマルションの科学” p. 210, （1971）朝倉畫店.

16) S. Matsumoto, Y.Kita and D. Yonezawa, J. Colloid Interface Sci., 57, 353 (1976)

17) N. Nelson, J.Biol. Chem., 153, 375 (1944) ; M. Somogyi, ib jd., 195, 19 (1952)

18) Y.Kita, S. Matsumoto and D. Yonezawa, J. Colloid Interface Sci., 62, 87 (1977).

19）喜多淑子, 松本幸雄, 米沢大造, 日本化学誌, No. 6, 748 (1977).

20）喜多淑子, 松本幸雄, 米沢大造, ib id 印刷中 
21）松本幸雄, 植田芳朗, 喜多淑子, 米沢大造, 日本 農芸化学会関西支部第 301 回講演会講演, 1977年 7 月.

22) S. Matsumoto, M. Kohda and S. Murata, J. Colloid Interface Sci., 62, 149 (1977).

23) M. Faure, Bull. Soc. Chim. Biol., 32, 503
(1950)

24) J.V.Boyd and P. Sherman, J. Colloid Iterface Sci., 34, 76 (1970) ; J.V.'Boyd, Dechema Monograph, 77, 125 (1974)

25）花井哲也, 私信 